\title{
Newborn screening for SMA in Southern Belgium
}

Citation for published version (APA):

Boemer, F., Caberg, J-H., Dideberg, V., Dardenne, D., Bours, V., Hiligsmann, M., Dangouloff, T., \& Servais, L. (2019). Newborn screening for SMA in Southern Belgium. Neuromuscular Disorders, 29(5), 343-349. https://doi.org/10.1016/j.nmd.2019.02.003

Document status and date:

Published: 01/05/2019

DOI:

10.1016/j.nmd.2019.02.003

Document Version:

Publisher's PDF, also known as Version of record

Document license:

Taverne

\section{Please check the document version of this publication:}

- A submitted manuscript is the version of the article upon submission and before peer-review. There can be important differences between the submitted version and the official published version of record.

People interested in the research are advised to contact the author for the final version of the publication, or visit the DOI to the publisher's website.

- The final author version and the galley proof are versions of the publication after peer review.

- The final published version features the final layout of the paper including the volume, issue and page numbers.

Link to publication

\footnotetext{
General rights rights.

- You may freely distribute the URL identifying the publication in the public portal. please follow below link for the End User Agreement:

www.umlib.nl/taverne-license

Take down policy

If you believe that this document breaches copyright please contact us at:

repository@maastrichtuniversity.nl

providing details and we will investigate your claim.
}

Copyright and moral rights for the publications made accessible in the public portal are retained by the authors and/or other copyright owners and it is a condition of accessing publications that users recognise and abide by the legal requirements associated with these

- Users may download and print one copy of any publication from the public portal for the purpose of private study or research.

- You may not further distribute the material or use it for any profit-making activity or commercial gain

If the publication is distributed under the terms of Article $25 \mathrm{fa}$ of the Dutch Copyright Act, indicated by the "Taverne" license above, 


\title{
Newborn screening for SMA in Southern Belgium
}

\author{
François Boemer ${ }^{\mathrm{a}, 1, *}$, Jean-Hubert Caberg ${ }^{\mathrm{b}, 1}$, Vinciane Dideberg ${ }^{\mathrm{b}}$, Domien Dardenne ${ }^{\mathrm{b}}$, \\ Vincent Bours $^{\mathrm{c}}$, Mickaël Hiligsmann ${ }^{\mathrm{d}}$, Tamara Dangouloffe,f, Laurent Servais ${ }^{\mathrm{e}, \mathrm{f}}$ \\ a Biochemical Genetics Lab, Department of Human Genetics, CHU of Liege, University of Liege, Liege 4000, Belgium \\ ${ }^{\mathrm{b}}$ Molecular Genetics Lab, Department of Human Genetics, CHU of Liege, University of Liege, Liege, Belgium \\ ${ }^{\mathrm{c}}$ Department of Human Genetics, CHU of Liege, University of Liege, Liege, Belgium \\ ${ }^{\mathrm{d}}$ Department of Health Services Research, CAPHRI Care and Public Health Research Institute, Maastricht University, Maastricht, The Netherlands \\ ${ }^{\mathrm{e}}$ I-Motion, Platform for Pediatric Clinical Trials, Arnold Trousseau Hospital, Paris, France \\ ${ }^{\mathrm{f}}$ Neuromuscular Center, CHR Citadelle, University of Liege, Liege, Belgium
}

Received 24 May 2018; received in revised form 7 February 2019; accepted 11 February 2019

\begin{abstract}
Approval was recently granted for a new treatment for spinal muscular atrophy (SMA). Given that the treatment is effective when administered early and the societal burden of SMA-related disability, the implementation of a newborn screening program is warranted. We describe the stepwise process that led us to launch a newborn screening program for SMA in Southern Belgium. Different political, ethical, and clinical partners were informed about this project and were involved in its governance, as were genetic and screening labs. We developed and validated a newborn screening method to specifically recognize homozygous deletions of exon 7 in the SMN1 gene. Subsequently, a 3 -year pilot study has been recently initiated in one Belgian neonatal screening laboratory to cover 17.000 neonates per year. Coverage extension to all of Southern Belgium to screen 55.000 babies each year is underway.
\end{abstract}

(C) 2019 Elsevier B.V. All rights reserved.

Keywords: Spinal muscular atrophy; Werdnig-Hoffmann disease; Newborn screening; SMN1; qPCR.

\section{Introduction}

Spinal muscular atrophy (SMA) is an inherited neuromuscular disorder that is characterized by the degeneration of motor neurons in the spinal cord and muscle atrophy. The spectrum of the SMA phenotype is stratified into five types depending on the age of onset, which can range from before birth to young adulthood. Motor neuron loss often results in severe muscle weakness, causing affected infants to die before 2 years of age (type 0 with neonatal onset, or type 1 in approximately $50 \%$ of all cases). Patients with milder forms of SMA exhibit muscle weakness that progressively worsens over several years (type 2-4) [1].

\footnotetext{
* Corresponding author.

E-mail address: f.boemer@chuliege.be (F. Boemer).

${ }^{1}$ Both authors contributed equally to this work.
}

SMA is caused by recessive mutations in the survival motor neuron 1 (SMN1) gene [2]. About 95\% of SMA cases are caused by homozygous deletions of exon 7 in $S M N 1$, whereas the remaining cases exhibit a heterozygous mutation on one allele and other deleterious variants on the other. The human genome harbors a paralogous gene, SMN2, that differs from SMN1 by only a few nucleotides including a $\mathrm{C}$ to $\mathrm{T}$ transition in exon 7 . This base change causes the skipping of exon 7 in most SMN2 transcripts. Approximately $90 \%$ of transcript isoforms encode a truncated unstable protein; full-length, functional SMN protein results from approximately $10 \%$ of SMN2 transcripts.

Recently, two phase 3 trials of nusinersen demonstrated increased event-free survival and motor milestone acquisition in patients with SMA types 1 [3] and 2 [4], leading to market authorization of this drug by the Food and Drug Administration and the European Medicines Agency among others. Type 1 patients with a disease course shorter than 
12 weeks are more likely to benefit from the treatment than type 1 patients for whom treatment is begun later [3]. In SMA type 2, patients younger than 6 years presented with better improvement upon treatment than did patients older than 6 years [4]. For patients with type 1 treated after the age of 7 months clinical improvement was of smaller amplitude than patients treated before 7 months [3,5-7]. A phase 2 trial is underway to examine the efficacy of multiple doses of nusinersen administered intrathecally in preventing or delaying the need for respiratory intervention or death in infants with genetically diagnosed and presymptomatic SMA (ClinicalTrials.gov identifier: NCT02386553).

In addition to nusinersen, other potential treatments have promise. A small uncontrolled study recently demonstrated the efficacy of gene replacement therapy in SMA type 1 [8], and a larger phase 3 non-controlled study is underway (NCT03461289). Phase 1-3 trials in SMA type 1 and SMA type 2 (ClinicalTrials.gov identifier: NCT02268552, NCT02908685, NCT02913482, NCT03032172) are currently being conducted using small molecules that interfere with the splicing of SMN2 [9]. These different therapeutic advances have led to the general understanding that management of SMA is changing considerably, from palliative and symptomatic care towards disease-modifying treatment.

Although the American College of Medical Genetics recommends routine carrier screening for SMA in the general population [10] and prenatal carrier screening pilot experiences have been conducted in some countries [11], population coverage of such initiatives remains currently limited. Given the physiopathology of the disease and data from pre-clinical models demonstrating rapid death of motor neurons [12], a large benefit of early intervention in affected patients is anticipated, and, indeed, this was demonstrated clinically in clinical trials of nusinersen [3] and gene therapy [10] as well as by the presentation of the intermediary results from the nusinersen pre-symptomatic study [13] and case reports [14]. Considering the efficiency of the new treatments when they are administered early and the societal costs of SMA-related disability [15], the implementation of newborn screening (NBS) programs for SMA appears ethically and medically obvious as long as the societal decision to reimburse a medication in SMA has been made. SMA is also now included in the Recommended Uniform Screening Panel, which is the official list of disorders to which US public health departments refer to screen newborns. To date, two pilot studies have already demonstrated the feasibility of population-based screening at affordable costs $[16,17]$.

We have developed a newborn screening method for SMA and initiated a 3-year pilot study implementing the program in Southern Belgium. The first babies were screened on March 5, 2018. Covering the full population of Southern Belgium would increase the number of screenings to approximately 55.000 births per year. The aim of this paper is to report the implementation of our SMA newborn screening program to facilitate similar initiatives in other countries.

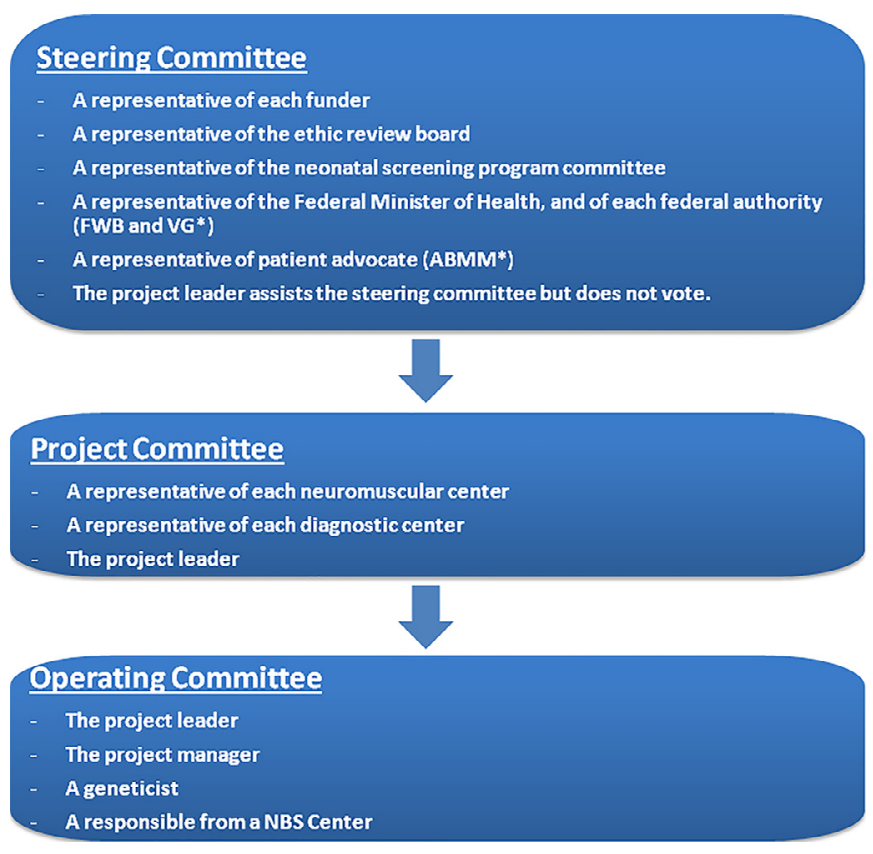

Fig. 1. Governance infrastructure for SMA newborn screening program. *FWB and VG: Federation Wallonie Bruxelles and Vlaams government; ABMM: Association Belge contre les Maladies neuro-Musculaires.

\section{Stepwise implementation of NBS program}

\subsection{Governance}

Initiated on September 1, 2017, our project was conducted through a clear governance system that included a steering board and both project and operative committees (Fig. 1). The steering board was composed of representatives of politicians, ethics experts, NBS specialists, funders, and patient associations. This committee supervised the overall project and ensured that it was conducted according to the initial plan and met ethical, legal, and scientific standards. The project committee, including representatives of neuromuscular and diagnostic centers, was in charge of project oversight. It approved amendments and oversaw the global management. The operating committee was composed of geneticists, NBS specialists, and the project leader.

\subsection{Engagement of community, politicians, and policy makers}

The implementation of this new NBS program was first promoted among different community partners. Political support was gathered over several meetings with politicians from different parties from both the regional and federal governments. The project was presented twice to the boards of the "Office de la Naissance et de l'Enfance" (ONE), the governmental agency in charge of NBS in Southern Belgium. ONE issued a positive opinion on the project. Accordingly, SMA was included in the list of disorders to be evaluated during the future revision of the NBS core panel in Southern 
Belgium. The Belgian patient advocacy group (Association Belge contre les Maladies Musculaires or ABMM) strongly supported the project. A Facebook page called "Sun May Arise on SMA" was created to inform followers about the project's progress. The project was regularly mentioned during conferences and received mainstream media coverage, which contributed to awareness among politicians and their eventual support.

\subsection{Ethical considerations}

Genetic population screening raises ethical concerns, and informed consent from the patients may be required based on the opinion of the local ethical review board (ERB). The project was orally discussed with the institutional ERB of Liege, which provided initial written guidance. The final project, taking this guidance into consideration, was finally approved on December 5, 2017 (B412201734396), in accordance with the Declaration of Helsinki. The ERB decision was that parents had the right to be informed that a screening procedure is conducted and that they have the right to refuse it, which is the standard procedure for all NBS in Southern Belgium.

The ERB also indicated that the framework of our project should not go beyond the prerogatives fixed by our steering authorities for official NBS, namely, the identification and the preventive support of a limited list of congenital disorders. In accordance with the criteria of Wilson and Jungner [18], our objective is limited to expanding the current NBS program to preemptively identify a newly treatable, well-known disorder: spinal muscular atrophy. The project does not identify heterozygous carriers, thus avoiding the corresponding ethical debate.

According to Southern Belgium current local legislation, general information on the NBS is systematically provided to all pregnant women, and the list of screened diseases is available on the website of the public agency in charge. The ERB deemed that parental information should not include the listing of screened diseases because the risk of inducing unjustified anxiety in a significant proportion of parents by listing 14 rare diseases far outweighs the aim of providing such extended information. Additionally, while strongly recommended, NBS is not mandatory in Southern Belgium: Parents are informed that they have then the right to refuse the newborn screening for their child. Accordingly, such opting-out is not disease-specific, but would concern the entire program. We should note that in Southern Belgium refusal of NBS is extremely rare.

The ERB also stated that informed consent is meaningful only if sufficient time is devoted to receiving it. Considering the psychological context (birth of a child) and the large proportion of non-French native speakers, the advantages of SMA screening cannot be comprehensively explained to "naive" parents, especially just after birth, in less than 15 min. Additional impediments to overcome before considering a meaningful systematic consent collection include developing an infrastructure to collect and store consent, and the time required to confirm the validity of the consent before conducting the analysis. In addition, inducing non-justified anxiety in parents with a limited ability to understand the non-targeted screening constitutes a risk that cannot be underestimated.

Ultimately, the ERB considered that the information regarding the SMA screening should not be different from that provided for any other newborn screening. Identifying the homozygous deletions of a single exon rather than a metabolic anomaly was not considered sufficient to change the overall philosophy of screening. Positive test results should be confirmed by testing an independent sample, with the appropriate patient information obtained by specific healthcare providers and after informed consent. The ERB recommended that heterozygous parents be informed about the risk of subsequent homozygous pregnancies but agreed that this could be considered in a second step.

This position was approved by the state agency in charge of NBS in Southern Belgium and the project was supported by the Belgian Council of Genetics.

\subsection{Patient flow}

The sample flowchart of SMA screening does not differ from that of systematic NBS in Southern Belgium. NBS cards are collected between 72 and $120 \mathrm{~h}$ of life, either in maternity wards or at home. The samples are addressed to the selected neonatal screening laboratories. No additional sampling is required because the residual blood spots collected for mandated NBS are sufficient for the SMA testing. After analysis, the dried blood spot (DBS) cards are stored over a five-year period, according to our local legislation.

As is the case in the event of positive results for other diseases, positive results for SMA will be simultaneously communicated by the screening laboratory both to the pediatrician and to referent neurologists in neuromuscular centers. The parents will be contacted on the same day by the referent neuro-pediatrician of the neuromuscular center, and a consultation will be planned as soon as possible to initiate confirmatory testing using an alternative technique. The result of this second testing performed on a second independent sample, realized after parents have signed an informed consent will be available at our center within three business days. Given the importance of concomitant SMN2 number of copies in SMA patient management [19], our confirmatory assay, involving a multiplex ligation-dependent probe amplification (MLPA) technique, will also provide information on neonate's SMN2 status.

In Belgium, nusinersen is reimbursed for patients with two or three copies of $S M N 2$. Patients can also be included in the Sprint trial (pre-symptomatic trial with gene therapy, NCT03505099). Patients with four copies can either opt for clinical surveillance or inclusion in Rainbowfish, a presymptomatic trial with splice modifiers (NCT pending). This is in agreement with a recent Delphi survey that recommended treatment for patients with two or three copies of $S M N 2$, and 
where no consensus was reached for patients with four copies of SMN2 [19].

There are eight neuromuscular reference centers in Belgium that cover the population of 10 million people. Three of these centers cover the French-speaking Belgium, and two of the pre-symptomatic studies for gene therapy and splice modifiers are being conducted in one of them. Ultimately, the decision of parents to include their infant in any therapeutic protocol will rely on information provided by their referent neuro-pediatrician within these centers. Because approximately $98 \%$ of parents of an affected child are heterozygous carriers of one SMN1 pathogenic variant [20], genetic counseling will also be offered to parents and at-risk family members.

\subsection{Funding}

The project was initially funded through a private donation. Subsequent support was provided by ABMM and other private donations addressed to $\mathrm{ABMM}$ and directed to the project. Additionally, grants were awarded from the Southern Belgium Ministry of Childhood and Investigator Initiated Trials were conducted by Avexis (a Novartis company), Biogen, and Roche.

\subsection{Technical setup}

Our analytical methodology relies on a qPCR assay of the $S M N 1$ gene on DNA extracted from DBS, using RPP30 as the reference gene (Additional file 1). SMN1 genotyping was designed to detect only homozygous deletions of exon 7 with a specific locked nucleic acid probe. Our method does not identify heterozygous carriers of the deletion, SMN1 point mutations, or the number of copies of the SMN2 modifier gene. The analytical method development was based on previous reports $[16,17]$. We designed the primers and probes used for the qPCR assay to decrease the cost and dependency on industrial producers.

To validate our assay, 53 SMA patients with homozygous deletions of SMN1 exon 7 identified by MLPA were sampled on DBS. DBS from 93 heterozygous carriers of the deletion (one compound heterozygous for the deletion and the pathogenic c.827A $>\mathrm{G}$ mutation) were also collected. All patients or guardians gave their informed consent to participate in the study. Concurrently, 1000 newborn screening samples were tested.

All samples were correctly characterized. The absence of fluorescence corresponding to the SMN1 probe was noted for all patients with homozygous deletions of exon 7 in $S M N 1$, and a significant signal was observed both for heterozygous and wild-type patients. Interestingly, among the 53 confirmed SMA samples, four patients carrying four copies of $S M N 2$ were correctly genotyped. We thus assume that our method is not affected by the number of copies of SMN2.

To interpret the results on a larger scale, the SMN1 results were integrated with the RPP30 amplification results by calculating the endpoint-fluorescence ratios. This approach rules out the presence of any polymerase inhibitors that could interfere with the qPCR. Based on endpoint-fluorescence scatter plots (Fig. 2), a genotypic dispersion plot (Fig. 3) was created that allowed us to define an unequivocal threshold to detect homozygous deletions. Based on results for this initial population, the cutoff for the SMN1/RPP3O ratio was fixed at 0.15 . This threshold is estimated to be highly reliable due to the large gap in the SMN1/RPP30 ratio between affected patients and individuals carrying at least one copy of exon 7. As stated previously, for ethical reasons, our method was not designed to identify carriers of the deletion and should not be used for this purpose because there is clearly a large overlap in the ratio between normal and heterozygous individuals.

The analytical costs, including material, reagents, and personnel expenses, were less than $3.00 € /$ newborn; therefore, the expenditures dedicated to including the SMA screening assay are reasonable and do not exceed the costs of other commonly accepted screenings (e.g., tandem-massspectrometry-related assays) [21]. Currently, because the sample number is modest (approximately 300 neonates per week), the DNA used for SMA testing is extracted manually. With larger population coverage in the future, process automation (i.e., the use of automatic DNA extraction), which would further decrease the cost and workload, will be warranted.

Since our screening method only identifies affected neonates carrying the homozygous deletions of exon 7 in SMN1, compound heterozygous patients carrying point mutations in $S M N 1$, accounting for approximately $5 \%$ of SMA cases, will be missed. The long-term risk associated with systematic SMA screening is that symptomatic SMA cases will become ultra-rare, and pediatricians will become less familiar with the clinical presentations of SMA. When the symptom recognition is less accurate, the diagnosis of SMA in neonates carrying point mutations could be significantly delayed in the far future. By that time, however, large-scale screening methods (i.e., next-generation sequencing) could possibly be more widespread, thus enabling the identification of such sporadic cases.

\subsection{Economic considerations}

The cost of nusinersen in Belgium is $88,298 €$ per vial. Were the alternative between NBS and treatment or no treatment, NBS would not be cost effective. However, nusinersen is currently reimbursed in all patients but the presymptomatic with four copies of $S M N 2$ and patients supported by permanent invasive ventilation. The alternative is thus between NBS and pre-symptomatic treatment of all cases with two or three copies of $S M N 2$ and post symptomatic treatment of patients whom parents opt for treatment rather than palliative care. In this situation, NBS for SMA is cost effective. Indeed, as reported by Klug et al. [15], the average annual cost of illness for SMA is estimated to be approximately $70,000 €$ per patient in 2013 for SMA type 3 


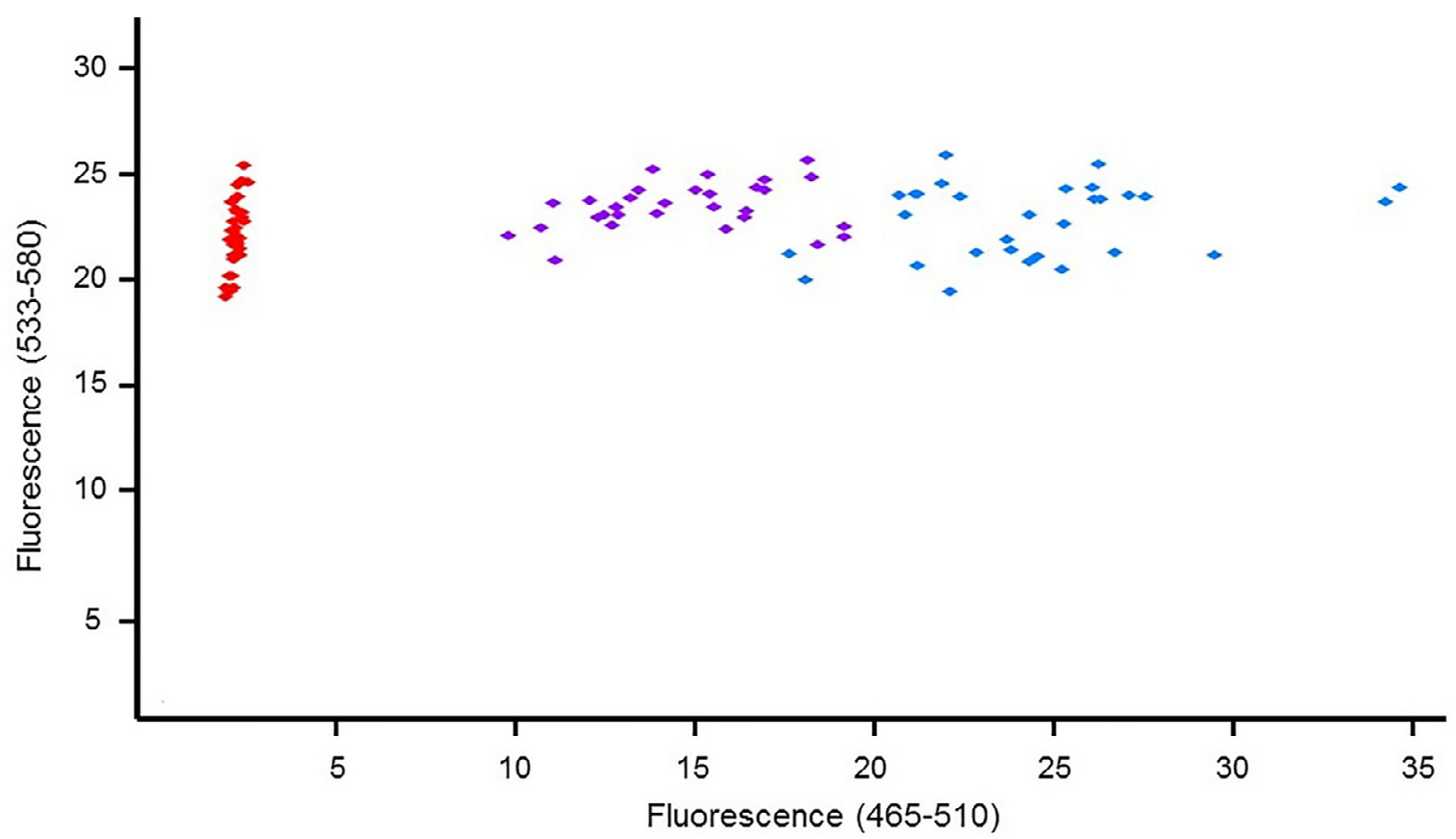

Fig. 2. Endpoint fluorescence scatter plot with $X$ coordinates representing fluorescence relative to $S M N 1$ amplification and $Y$ coordinates representing fluorescence relative to RPP30 amplification. Red points correspond to 30 DBS samples carrying a homozygous deletion of SMN1 exon 7. Purple points represent 30 DBS samples carrying a heterozygous deletion of SMN1 exon 7. Blue points illustrate 30 wild-type DBS samples.

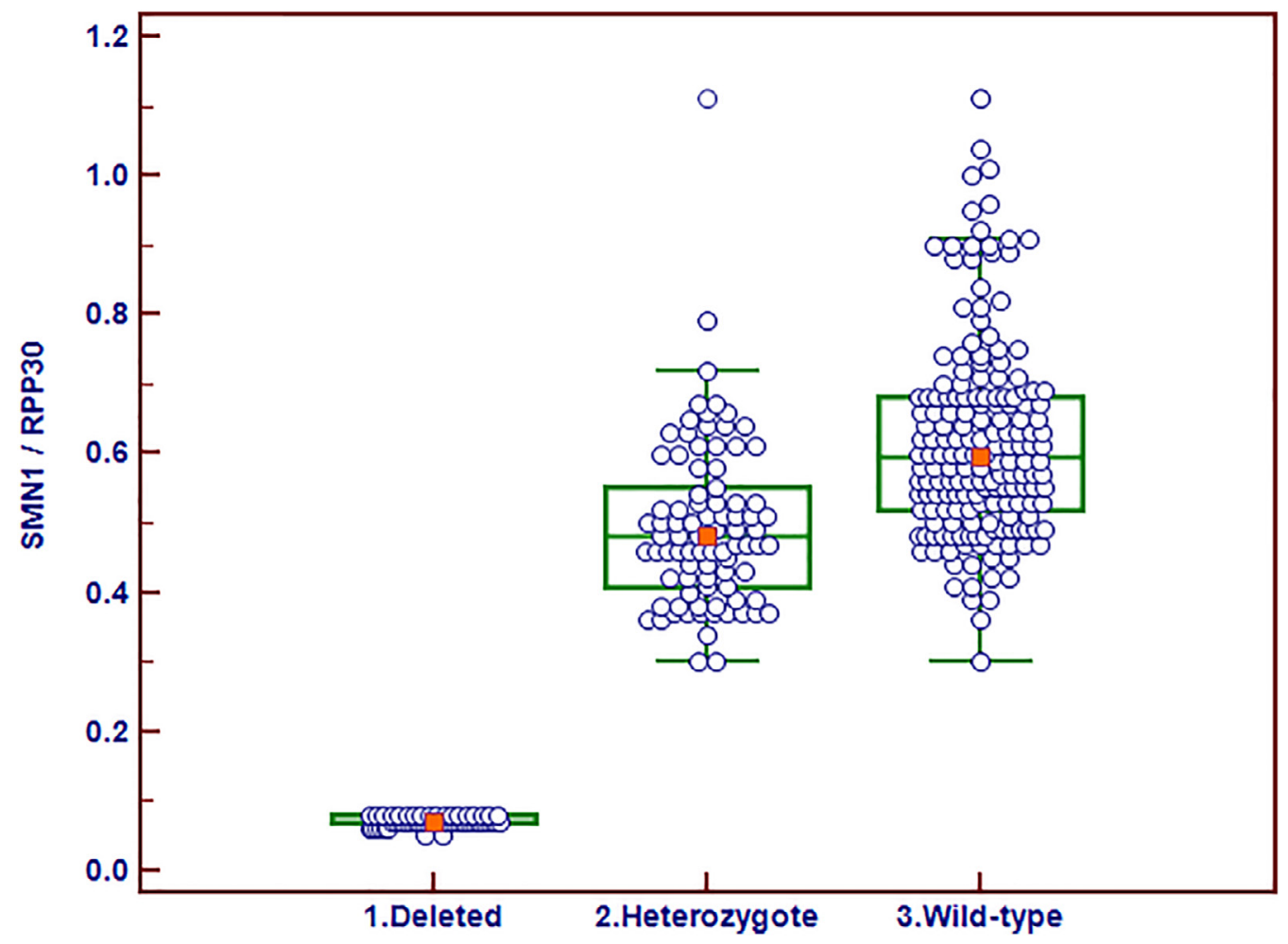

Fig. 3. Box-and-whisker plot of the ratio of $S M N 1$ to RPP30 endpoint fluorescence for different genotypes: wild-type $(n=1000)$, heterozygous $(n=93)$, and homozygous deletion of exon 7 in SMN1 $(n=53)$. 
and $90.000 €$ for type 2 . The authors stated that their results suggested a notable potential for reducing the overall costs of treating the illness and improving the health-related quality of life if the therapeutic intervention could lead to a less severe course of the disease. Disease burden for families in terms of hospitalization and life impact was confirmed in a recent natural history study [22].

Since interim results from the NURTURE study indicate that patients treated with nusinersen before the appearance of symptoms achieve a normal (for patients with three copies of $S M N 2$ ) or nearly normal (for patients with two copies of $S M N 2$ ) motor development with a therapeutic effect far above the one observed in post-symptomatically treated patients [13], it is thus not unreasonable to speculate that a presymptomatic intervention will yield better cost-effectiveness than post-symptomatic care, provided that patients treated pre-symptomatically would have been treated after the appearance of symptoms.

To better assess the issue of cost-effectiveness, a medico-economic analysis is embedded in our NBS program. Integrated evaluation of both costs of the treatment and expenditures for patient care will provide a clear overview of societal costs of screening. Whether or not NBS will lead to an increase in the number of treated patients remains to be demonstrated. Outcomes of the cost-effectiveness assessment will allow decision makers to decide whether or not to extend the project beyond the pilot phase. For comparison, neonatal screening for cystic fibrosis is a well-accepted program, even though quantifying its cost-benefit still remains challenging despite a large number of empirical studies reporting longterm outcomes in both screened and unscreened cohorts [23].

\subsection{Communication}

The entire planning and implementation process for SMA screening could be followed on the Facebook page, which also noted that the Belgian Patients Advocacy group ABMM was collecting donations for the project. National press groups were notified when the first baby was screened on March 05, 2018, leading to national newspaper press releases and radio interviews that further informed the general population about this new program. All reactions on the Facebook page and online media were positive.

\section{Conclusions}

We share here our experience regarding the rapid implementation of a genetic-based newborn screening program for SMA. Our governance system was established on September 1, 2017, and the first babies were screened 6 months later, on March 5, 2018. The Southern Belgian organization of NBS and neuromuscular centers were suited to this rapid achievement. The position of the ERB, which considered the pros and the risks of signing consent, considerably supported the rapid advancement of the program. We anticipate that the position of the Belgian ERB could benchmark similar positions elsewhere and facilitate the acceptance of SMA screening. The introduction of qPCR techniques into our NBS program, first implemented as described here for SMA, could be broadened in the near future to the screening for severe combined immunodeficiencies or other genetic disorders. Our pilot study will be conducted over the next three years, following which the healthcare authorities will have to determine whether testing for SMA as part of newborn screening will continue. A concomitant medico-economic assessment is embedded to this project to inform decision-making in Belgium and other countries regarding the medical and economic value of the program.

\section{Ethics approval and consent to participate}

Ethical approval (reference B412201734396) was obtained from the Institutional Review Board (Ethical Committee of the hospital CHR Citadelle, Liège, Belgium), in compliance with the Declaration of Helsinki. All patients or guardians gave informed consent to participate in the study.

\section{Competing interests}

LS is member of Biogen, AveXis, Roche and Cytokinetics Scientific advisory boards and has provided consultancy to Roche, Avexis and Biogen. The other authors have no financial disclosures relevant to this article. The authors declare that they have no competing interests.

\section{Funding}

This pilot study is supported by Biogen, AveXis, and the ABMM (Association Belge contre les Maladies neuroMusculaires), Minister's Office Alda GREOLI (WalloniaBrussels Community)

\section{Acknowledgments}

Authors thank the paramedical team of the Neuromuscular Center at CHR Citadelle and the technical team of the Biochemical Genetics Laboratory at CHU Liege.

\section{Supplementary material}

Supplementary material associated with this article can be found, in the online version, at doi:10.1016/j.nmd.2019.02. 003.

\section{References}

[1] Kaufmann P, McDermott MP, Darras BT, Finkel R, Kang P, Oskoui M, et al. Observational study of spinal muscular atrophy type 2 and 3: functional outcomes over 1 year. Arch Neurol 2011;68:779-86. doi:10. 1001/archneurol.2010.373.

[2] Lefebvre S, Bürglen L, Reboullet S, Clermont O, Burlet P, Viollet L, et al. Identification and characterization of a spinal muscular atrophydetermining gene. Cell 1995;80:155-65. doi:10.1016/0092-8674(95) 90460-3. 
[3] Finkel RS, Mercuri E, Darras BT, Connolly AM, Kuntz NL, Kirschner J, et al. Nusinersen versus Sham control in infantile-onset spinal muscular atrophy. N Engl J Med 2017;377:1723-32. doi:10.1056/ NEJMoa1702752.

[4] Mercuri E, Darras BT, Chiriboga CA, Day JW, Campbell C, Connolly AM, et al. Nusinersen versus Sham control in later-onset spinal muscular atrophy. N Engl J Med 2018;378:625-35. doi:10.1056/ NEJMoa1710504.

[5] Pechmann A, Langer T, Schorling D, Stein S, Vogt S, Schara U, et al. Evaluation of children with SMA Type 1 under treatment with nusinersen within the expanded access program in Germany. J Neuromuscul Dis 2018. doi:10.3233/JND-180315.

[6] Pane M, Palermo C, Messina S, Sansone VA, Bruno C, Catteruccia M, et al. Nusinersen in type 1 SMA infants, children and young adults: preliminary results on motor function. Neuromuscul Disord 2018;28:582-5. doi:10.1016/j.nmd.2018.05.010.

[7] Aragon-Gawinska K, Seferian AM, Daron A, Gargaun E, Vuillerot C, Cances $\mathrm{C}$, et al. Nusinersen in patients older than 7 months with spinal muscular atrophy type 1: a cohort study. Neurology 2018;91:e1312-18. doi:10.1212/WNL.0000000000006281.

[8] Mendell JR, Al-Zaidy S, Shell R, Arnold WD, Rodino-Klapac LR, Prior TW, et al. Single-dose gene-replacement therapy for spinal muscular atrophy. N Engl J Med 2017;377:1713-22. doi:10.1056/ NEJMoa1706198.

[9] Naryshkin NA, Weetall M, Dakka A, Narasimhan J, Zhao X, Feng Z, et al. SMN2 splicing modifiers improve motor function and longevity in mice with spinal muscular atrophy. Science 2014;345:688-93 (80-). doi:10.1126/science. 1250127.

[10] Prior TWProfessional Practice and Guidelines Committee. Carrier screening for spinal muscular atrophy. Genet Med 2008;10:840-2. doi:10.1097/GIM.0b013e318188d069.

[11] Su Y-N, Hung C-C, Lin S-Y, Chen F-Y, Chern JPS, Tsai C, et al. Carrier screening for spinal muscular atrophy (SMA) in 107,611 pregnant women during the period 2005-2009: a prospective populationbased cohort study. PLoS One 2011;6:e17067. doi:10.1371/journal.pone. 0017067.

[12] Govoni A, Gagliardi D, Comi GP, Corti S. Time is motor neuron: therapeutic window and its correlation with pathogenetic mechanisms in spinal muscular atrophy. Mol Neurobiol 2018:1-12. doi:10.1007/ s12035-017-0831-9.
[13] Bertini E, Hwu W-L, Reyna SP, Farwell W, Gheuens S, Sun P, et al. Efficacy and safety of nusinersen in infants with presymptomatic spinal muscular atrophy (SMA): interim results from the NURTURE study. Eur J Paediatr Neurol 2017;21:e14. doi:10.1016/j.ejpn.2017.04.1218.

[14] Gidaro T, Servais L. Nusinersen treatment of spinal muscular atrophy: current knowledge and existing gaps. Dev Med Child Neurol 2018. doi:10.1111/dmcn.14027.

[15] Klug C, Schreiber-Katz O, Thiele S, Schorling E, Zowe J, Reilich P, et al. Disease burden of spinal muscular atrophy in Germany. Orphanet J Rare Dis 2016;11:58. doi:10.1186/s13023-016-0424-0.

[16] Chien YH, Chiang SC, Weng WC, Lee NC, Lin CJ, Hsieh WS, et al. Presymptomatic diagnosis of spinal muscular atrophy through newborn screening. J Pediatr 2017;190:124-9 e1. doi:10.1016/j.jpeds.2017.06. 042 .

[17] Kraszewski JN, Kay DM, Stevens CF, Koval C, Haser B, Ortiz V, et al. Pilot study of population-based newborn screening for spinal muscular atrophy in New York state. Genet Med 2017. doi:10.1038/gim.2017.152.

[18] Wilson JMG, Jungner G. Principles and practice of screening for disease. Geneva: WHO; 1968.

[19] Glascock J, Sampson J, Haidet-Phillips A, Connolly A, Darras B, Day J, et al. Treatment algorithm for infants diagnosed with spinal muscular atrophy through Newborn screening. J Neuromuscul Dis 2018;26:1-14. doi:10.3233/JND-180304.

[20] Wirth B, Schmidt T, Hahnen E, Rudnik-Schöneborn S, Krawczak M, Müller-Myhsok B, et al. De novo rearrangements found in $2 \%$ of index patients with spinal muscular atrophy: mutational mechanisms, parental origin, mutation rate, and implications for genetic counseling. Am J Hum Genet 1997;61:1102-11. doi:10.1086/301608.

[21] Feuchtbaum L, Cunningham G. Economic evaluation of tandem mass spectrometry screening in California. Pediatrics 2006;117:S280-6. doi:10.1542/peds.2005-2633G

[22] Chabanon A, Seferian AM, Daron A, Péréon Y, Cances C, Vuillerot C, et al. Prospective and longitudinal natural history study of patients with Type 2 and 3 spinal muscular atrophy: baseline data NatHis-SMA study. PLoS One 2018;13:e0201004. doi:10.1371/journal.pone.0201004.

[23] Grosse SD. Showing value in newborn screening: challenges in quantifying the effectiveness and cost-effectiveness of early detection of phenylketonuria and cystic fibrosis. Healthcare 2015;3:1133-57. doi:10.3390/healthcare3041133. 